\section{Combined 23-gauge microincisonal vitrectomy surgery and phacoemulsification with AcrySof toric intraocular lens implantation: a comparative study}

DH Park', JP Shin ${ }^{1}$ and SY Kim²

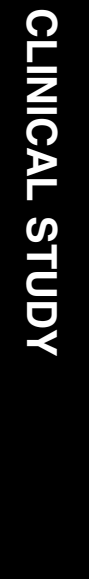

Conclusions Combined 23-gauge MIVS and phacoemulsification with AcrySof toric IOL implantation is an effective method of correcting vitreoretinal diseases and cataract and pre-existing corneal astigmatism, and the toric IOL showed good rotational stability, even in vitrectomized eyes for 6 months. Eye (2011) 25, 1327-1332; doi:10.1038/eye.2011.168; published online 15 July 2011

Keywords: toric intraocular lens; corneal astigmatism; IOL rotation; phacovitrectomy

Introduction

The presence of cataracts often necessitates a second operation soon after vitrectomy if lens extraction is not performed simultaneously with vitrectomy. Furthermore, vitrectomy itself causes cataract progression. Thus, combined phacovitrectomy is an effective and safe procedure to handle both cataract and vitreoretinal diseases. ${ }^{1-3}$ However, corneal contour is significantly changed causing postoperative astigmatism by 20 -gauge vitrectomy. ${ }^{4-6}$ Recently, 23-gauge microincisional vitrectomy surgery (MIVS) had less surgically induced astigmatism (SIA) compared with 20-gauge vitrectomy. ${ }^{7}$ However, it could not correct pre-existing corneal astigmatism.

There are many options for treating pre-existing corneal astigmatism including excimer laser refractive procedures and astigmatic keratotomy using limbal or corneal
${ }^{1}$ Department of Ophthalmology, School of Medicine, Kyungpook National University, Chung-gu, Daegu, South Korea

${ }^{2}$ Nune Eye Hospital, Daegu, South Korea

Correspondence: SY Kim, Nune Eye Hospital, 41-3, Beomeo-dong, Suseong-gu, Daegu 706-010, South Korea

Tel: + 8253420 5817; Fax: + 82534266552

E-mail: kimsy@knu.ac.kr

Received: 22 December 2010

Accepted in revised form: 24 May 2011 Published online: 15 July 2011 
relaxing incisions. All these methods have limitations including the degree of treatable astigmatism and longterm instability. Additionally, it is difficult to do the above procedures concurrently with vitrectomy.

Toric intraocular lens (IOL) implantation is another option for correcting astigmatism. Several studies mentioned various toric IOLs and found this method effective in correcting astigmatism. ${ }^{8-10}$ Plate haptic and loop haptic toric IOLs have been used for about a decade, but are associated with postoperative rotational instability. ${ }^{11}$ Recently, AcrySof toric IOL (Alcon Laboratories, Inc., Fort Worth, TX, USA) had good rotational stability and favorable efficacy in patients with cataracts and corneal astigmatism. ${ }^{12-14}$

To our knowledge, combined phacovitrectomy and toric IOL implantation in patients who had both cataract with a pre-existing astigmatism and vitreoretinal diseases has never been reported before. The purpose of this study was to evaluate combined 23-gauge MIVS and phacoemulsification with AcrySof toric IOL implantation with comparison to non-toric IOL.

\section{Patients and methods}

\section{Patients and study design}

This prospective nonrandomized comparative interventional study enrolled 35 consecutive patients (35 eyes) who had preoperative regular corneal astigmatism greater than 1 diopter (D) and combined phacoemulsification and 23-gauge MIVS from September 2009 to May 2010.

The study was carried out in accordance with the Declaration of Helsinki, and the study protocol was approved by the Institutional Review Board of Kyungpook National University Hospital. All patients were informed of the procedure and informed consent was obtained.

The inclusion criteria were as follows: patients with cataract and vitreoretinal diseases requiring vitrectomy; age between 60 and 85 years; preoperative regular corneal astigmatism greater than $1 \mathrm{D}$; need for spherical IOL correction between $1625 \mathrm{D}$; and pupil dilation $\geq 6 \mathrm{~mm}$.

The exclusion criteria were as follows: patients with previous history of ocular surgery, amblyopia, glaucoma, uveitis, and optic atrophy; irregular corneal astigmatism or pre-existing corneal pathology; complicated vitreoretinal diseases including proliferative vitreoretinopathy and rhegmatogenous, or tractional retinal detachment; patients with age-related macular degeneration or neovascular glaucoma; patients with poor vision precluding proper fixation for keratometry; patients with dense cataract and severe vitreous hemorrhage precluding refraction or optical biometry; and patients who needed gas or silicone oil tamponade at the end of vitrectomy.

Patients who met the above criteria and accepted AcrySof toric IOL implantation at the end of vitrectomy were assigned to the toric IOL group. Patients who refused the toric IOL implantation had foldable $6.0 \mathrm{~mm}$ hydrophilic IOL (Akreos AO MI60; Bausch \& Lomb, Rochester, NY, USA) implantation and were assigned to the non-toric IOL group.

Each patient had preoperative ophthalmic examinations including monocular uncorrected visual acuity (UCVA) and best-corrected visual acuity (BCVA) using Snellen chart, refraction using autorefractometry (Topcon KR-8100; Topcon Co. Ltd, Tokyo, Japan), keratometry, and optical biometry using Zeiss Humphrey IOLMaster (Version 5.02; Carl Zeiss Meditec Ltd, Jena, Germany), computerized corneal topography using Orbscan topography system II (Bausch \& Lomb, Salt Lake City, UT, USA), and fundus examination using 78-D lens. Fluorescein angiography was conducted in patients with proliferative diabetic retinopathy (PDR).

In both groups, the IOL spherical power was calculated for each case using SRK/T formula in eyes with axial length $\geq 22 \mathrm{~mm}$, and the targeted refraction was emmetropia. In the toric IOL group, the IOL cylinder power and alignment axis were calculated using a web-based toric IOL calculator program (available at: http:/ / www.acrysoftoriccalculator.com) taking into account the keratometry readings and mandatory data input on the position of the incision and the SIA by superior incision $(0.30 \mathrm{D})$, which was measured from our previous investigation. ${ }^{7}$

The manufacturer's information shows the SN60T3, SN60T4, and SN60T5 toric IOLs are intended for use when pre-existing corneal astigmatisms lie between $0.75 \mathrm{D}$ and $1.50 \mathrm{D}, 1.75 \mathrm{D}$ and $2 \mathrm{D}$, and 2.25 D and $2.50 \mathrm{D}$, respectively.

\section{Surgical technique}

The surgery was performed by one surgeon (SK). In the toric IOL group, preoperatively, the Nuijts/Lane preoperative toric reference corneal marker (AE-2793S; ASICO) was used to place three limbal reference marks at 9,12 , and 3 o'clock with the patient sitting upright. In both groups, the surgery was started by sclerotomy with a 23-gauge stiletto blade. The microcannula was inserted using a blunt inserter (DORC, Auidland, The Netherlands). All of the eyes had phacoemulsification using Infinity Vision System (Alcon Laboratories) through $2.2 \mathrm{~mm}$ superior corneal incision. The target capsulorrhexis diameter was $5.50 \mathrm{~mm}$ ensuring overlap of the IOL border. After 
phacoemulsification and irrigation/aspiration, the capsular bag was expanded with viscoelastic material. Furthermore, 23-gauge MIVS procedures were carried out using Accurus Vitrectomy System (Alcon) including core vitrectomy, epiretinal membrane (ERM) peeling, or fibrovascular membrane dissection. Endolaser photocoagulation was performed to complete panretinal photocoagulation for PDR, and focal photocoagulation was added for diabetic macular edema (DME). In the toric IOL group, after vitrectomy was completed, the actual implantation axis was marked using an Intra-op toric axis marker (AE-2792; ASICO) and AcrySof toric IOL was implanted through an extended $2.75 \mathrm{~mm}$ superior corneal incision with a Monarch II injector (Alcon). The IOL was dialed $\sim 15^{\circ}$ off axis before the viscoelastic material removal. After removal of viscoelastic material, the IOL was rotated to align the cylinder axis with the marked axis. In the non-toric IOL group, implantation of a hydrophilic IOL (Akreos AO MI60; Bausch \& Lomb) was carried out without wound extension. In both groups, removal of the microcannulas was carried out without suturing the main corneal wound and sclerotomy sites. At the end of surgery, intravitreal injection of $1.25 \mathrm{mg}(0.05 \mathrm{ml})$ bevacizumab (Avastin; Genentech, South San Francisco, CA, USA) was performed for PDR from both groups.

\section{Postoperative evaluations}

Monocular UCVA and BCVA, refraction, keratometry, and fundus examination were conducted at postoperative week 1 and at months 1, 3, and 6. With IOLMaster keratometric readings, SIA consisting of astigmatic amplitude and axis was calculated by the difference between the preoperative and postoperative astigmatism by the rectangular coordinate method using the Holladay-Cravy-Koch formula. ${ }^{15}$ In the toric IOL group, the IOL axis was measured using the vertical arm readings of the slit lamp (Haag-Streit BQ-900; Bern, Switzerland) through dilated pupil with tropicamide. A thin coaxial slit was projected in front of the eye and rotated until the thin slit projection overlapped the axis marks of the toric IOL. All of the postoperative evaluations were carried out by one ophthalmologist (JS) who had no knowledge of which group each patient was in both before and after surgery, of the pre-operative data, and of the intended IOL axis.

For statistical analysis, Snellen visual acuity was converted to the logarithm of the minimum angle of resolution (logMAR).

\section{Statistical analysis}

Chi-square test and Mann-Whitney $U$-test were used to compare data between the two groups. Statistical analyses were carried out using SPSS statistical software (version 14.0; SSPS Inc., Chicago, IL, USA). For all statistical tests, $P<0.05$ was considered significant.

Assuming an inter-group residual refractive cylinder difference of $0.50 \mathrm{D}(\mathrm{SD}=0.5 \mathrm{D})$ would be clinically meaningful, the required sample size in each group is 15 patients with a statistical significance of $5 \%$, a power of $80 \%$, and a drop rate of $10 \%$.

\section{Results}

A total of 35 eyes from 35 consecutive patients were enrolled. Five patients were excluded because of preoperative or intraoperative exclusion criteria and loss of follow-up. A total of 30 eyes (30 patients) participated in this study including 15 eyes for toric IOL group and 15 eyes for non-toric IOL group. Demographics and clinical data of the patients are summarized in Table 1. Indication of vitrectomy included three eyes of idiopathic ERM and 27 eyes of severe PDR with or without DME. There were no statistically significant differences between the two groups in age, gender, indication of vitrectomy, preoperative BCVA, absolute refractive cylinder, and axial length $(P>0.05$, respectively). Eight eyes $(53.4 \%)$ had implantation of SN60T3, 2 eyes (13.3\%) had SN60T4, and 5 eyes $(33.3 \%)$ had SN60T5 IOL.

Table 1 Demographics and preoperative clinical data

\begin{tabular}{lccc}
\hline & $\begin{array}{c}\text { Toric IOL } \\
\text { group }\end{array}$ & $\begin{array}{c}\text { Non-toric } \\
\text { IOL group }\end{array}$ & P-value \\
& $15(15)$ & $15(15)$ & \\
No. of eyes (patients) & $6 / 9$ & $7 / 8$ & $1.0^{\mathrm{a}}$ \\
Gender (Male/Female) & $65.1 \pm 4.3$ & $66.3 \pm 5.4$ & $0.512^{\mathrm{b}}$ \\
Age (years) & & & \\
& $2(13.3)$ & $1(6.6)$ & $0.815^{\mathrm{a}}$ \\
Indication of vitrectomy, no. (\%) & $7(46.7)$ & $7(46.7)$ & \\
$\quad$ Idiopathic ERM & $6(40.0)$ & $7(46.7)$ & \\
PDR with DME & $0.87 \pm 0.23$ & $0.79 \pm 0.28$ & $0.424^{\mathrm{b}}$ \\
PDR without DME & $1.94 \pm 0.56$ & $1.82 \pm 0.46$ & $0.267^{\mathrm{b}}$ \\
Mean BCVA (logMAR) & & & \\
Mean absolute refractive & $23.0 \pm 0.8$ & $23.4 \pm 0.6$ & $0.090^{\mathrm{b}}$ \\
cylinder (D) & & & \\
Mean axial length (mm) & & & \\
& & & \\
Type of toric IOL & $2(13.3)$ & & \\
T3 & $5(33.3)$ & & \\
T4 & & & \\
T5 & &
\end{tabular}

Abbreviations: BCVA, best-corrected visual acuity; D, diopters; DME, diabetic macular edema; ERM, epiretinal membrane; IOL, intraocular lens; $\log \mathrm{MAR}, \operatorname{logarithm}$ of the minimum angle of resolution; PDR, proliferative diabetic retinopathy; T3, AcrySof SN60T3 IOL (1.50 D at IOL plane); T4, AcrySof SN60T4 IOL (2.25 D at IOL plane); T5, AcrySof SN60T5 IOL (3.0 D at IOL plane)

${ }^{a}$ Chi-square test.

bMann-Whitney U-test. 
Table 2 Changes in uncorrected visual acuity (UCVA) and best-corrected visual acuity (BCVA) between toric intraocular lens (IOL) group and non-toric IOL group

\begin{tabular}{|c|c|c|c|c|c|}
\hline & \multicolumn{2}{|c|}{ Toric IOL group } & \multicolumn{2}{|c|}{ Non-toric IOL group } & \multirow{2}{*}{$\begin{array}{l}\text { P-value } \\
\text { (UCVA/BCVA) }\end{array}$} \\
\hline & UCVA & $B C V A$ & UCVA & $B C V A$ & \\
\hline Preoperative & $0.89 \pm 0.20$ & $0.87 \pm 0.23$ & $0.79 \pm 0.28$ & $0.79 \pm 0.28$ & $0.412 / 0.424$ \\
\hline \multicolumn{6}{|l|}{ Postoperative } \\
\hline 1 week & $0.55 \pm 0.24$ & $0.52 \pm 0.25$ & $0.64 \pm 0.26$ & $0.50 \pm 0.14$ & $0.367 / 0.744$ \\
\hline 1 month & $0.29 \pm 0.10$ & $0.26 \pm 0.18$ & $0.62 \pm 0.24$ & $0.25 \pm 0.12$ & $<0.001 / 1.0$ \\
\hline 3 months & $0.24 \pm 0.11$ & $0.21 \pm 0.11$ & $0.61 \pm 0.26$ & $0.22 \pm 0.11$ & $<0.001 / 0.713$ \\
\hline 6 months & $0.23 \pm 0.12$ & $0.20 \pm 0.10$ & $0.61 \pm 0.23$ & $0.21 \pm 0.11$ & $<0.001 / 0.653$ \\
\hline
\end{tabular}

Abbreviations: $\mathrm{BCVA}$, best-corrected visual acuity; IOL, intraocular lens; UCVA, uncorrected visual acuity.

${ }^{a}$ Comparison of toric IOL group and non-toric IOL group with regards to UCVA and BCVA, respectively by Mann-Whitney $U$-test.

Values are presented as mean \pm SD.

Visual acuity is presented as logarithm of the minimum angle of resolution (logMAR).

\section{Visual outcomes}

There was no difference in UCVA at preoperative period and at postoperative week 1 between the two groups $(P=0.412$. and 0.367 , respectively) (Table 2 ). However, the UCVA of the toric IOL group was significantly better than the non-toric IOL group at postoperative months 1 , 3 , and 6 ( $P<0.001$, respectively). There was no difference in BCVA between the two groups at each follow-up period ( $P>0.05$, respectively).

\section{Refractive cylinder}

At postoperative month 6 , the mean absolute residual refractive cylinder was $0.57 \pm 0.26 \mathrm{D}$ in the toric IOL and $1.50 \pm 0.46 \mathrm{D}$ in the non-toric IOL group (Table 3 ). The mean absolute residual refractive cylinder of the toric IOL group at postoperative week 1 , and months 1,3 , and 6 was less than the non-toric IOL group $(P=0.008$, $<0.001,<0.001$, and $<0.001$, respectively).

\section{Surgically induced astigmatism (SIA)}

At postoperative week 1 , the mean SIA was $1.05 \pm 0.32 \mathrm{D}$ in the toric IOL and $1.09 \pm 0.25 \mathrm{D}$ in the non-toric IOL group (Table 4). At postoperative month 6, the mean SIA was $0.26 \pm 0.19 \mathrm{D}$ in the toric IOL and $0.27 \pm 0.15 \mathrm{D}$ in the non-toric IOL group. There was no difference between the two groups at each postoperative period $(P>0.05$, respectively).

\section{Rotational stability}

The mean absolute toric IOL axis rotation was $3.52 \pm 2.75^{\circ}$ at postoperative month 6 . The IOL rotation was within $5^{\circ}$ in 10 eyes $(66.7 \%)$ and within $10^{\circ}$ in 15 eyes (100.0\%). No eyes were required IOL readjustment because of misalignment problems.
Table 3 Changes in absolute residual refractive cylinder (Diopter) at each postoperative period

\begin{tabular}{lccr}
\hline & $\begin{array}{c}\text { Toric IOL } \\
\text { group }\end{array}$ & $\begin{array}{c}\text { Non-toric } \\
\text { IOL group }\end{array}$ & P-value $^{\mathrm{a}}$ \\
\hline Preoperative & $1.94 \pm 0.56$ & $1.82 \pm 0.46$ & 0.267 \\
& & & \\
Postoperative & $1.06 \pm 0.57$ & $1.65 \pm 0.49$ & 0.008 \\
1 week & $0.72 \pm 0.42$ & $1.53 \pm 0.47$ & $<0.001$ \\
1 month & $0.60 \pm 0.31$ & $1.52 \pm 0.45$ & $<0.001$ \\
3 months & $0.57 \pm 0.26$ & $1.50 \pm 0.46$ & $<0.001$ \\
6 months & & & \\
\hline
\end{tabular}

Abbreviation: IOL, intraocular lens.

${ }^{a}$ Comparison of toric IOL group and non-toric IOL group with regards to mean absolute residual refractive cylinder by Mann-Whitney $U$-test. Values are presented as mean $\pm \mathrm{SD}$.

Table 4 Changes in surgically induced astigmatism (SIA) (Diopter) at each postoperative period

\begin{tabular}{lccc}
\hline & $\begin{array}{c}\text { Toric IOL } \\
\text { group }\end{array}$ & $\begin{array}{c}\text { Non-toric } \\
\text { IOL group }\end{array}$ & P-value $^{\text {a }}$ \\
\hline Postoperative & & & \\
$\quad 1$ week & $1.05 \pm 0.32$ & $1.09 \pm 0.25$ & 0.624 \\
1 month & $0.64 \pm 0.23$ & $0.63 \pm 0.19$ & 0.838 \\
3 months & $0.32 \pm 0.17$ & $0.31 \pm 0.20$ & 0.935 \\
6 months & $0.26 \pm 0.19$ & $0.27 \pm 0.15$ & 0.653 \\
\hline
\end{tabular}

Abbreviation: SIA, surgically induced astigmatism calculated by rectangular coordinate method using the Holladay-Cravy-Koch formula.

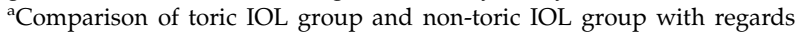
to SIA by Mann-Whitney $U$-test.

Values are presented as mean \pm SD.

\section{Complications}

No eyes had postoperative complications related to MIVS including postoperative hypotony, postoperative vitreous hemorrhage, recurrent ERM or DME, and endophthalmitis during the 6 months. No eyes had 
complications related to phacoemulsification including zonular dialysis, posterior capsule rupture, persistent corneal edema, or posterior capsule opacification. No eyes required a secondary intervention.

\section{Discussion}

Combined phacovitrectomy has been an effective and safe procedure for patients with both cataract and vitreoretinal diseases. However, 20-gauge vitrectomy can cause postoperative astigmatism significantly by sclerotomy sites sutures and scleral cauterization. 6,16 A previous study reported that mean SIA in combined 2.2-mm small incision phacoemulsification and 23-gauge MIVS was significantly less than 20-gauge vitrectomy, and it was $1.07,0.63,0.47$, and $0.33 \mathrm{D}$ at postoperative weeks $1,4,8$, and $12 .{ }^{7}$ Bauer et $a l^{12}$ reported that the mean SIA of eyes, which had only phacoemulsification with AcrySof toric IOL implantation, ranged from 0.61 to $1.28 \mathrm{D}$ at 4 months. Thus, the authors presumed that the SIA of 23-gauge MIVS would not affect significantly the astigmatic reduction of the toric IOL. Although the main corneal wound size was $2.75 \mathrm{~mm}$ in the toric IOL group in the present study, mean SIA was $1.05,0.64,0.32$, and $0.26 \mathrm{D}$ at postoperative week 1 , and months 1,3 , and 6 . Thus, 23-gauge MIVS is not a considerable factor that affects the final SIA when treating pre-existing corneal astigmatism with vitreoretinal diseases.

Key findings in this study were rotational stability of toric IOL, even in vitrectomized eyes and better UCVA compared with the non-toric IOL group. Rotation of a toric IOL from its intended orientation degrades its corrective power, with $\sim 3.3 \%$ loss of cylindrical power for every degree off axis. ${ }^{17}$ When the toric IOL rotates $30^{\circ}$, the cylinder power is completely lost. Thus, rotation of the toric IOL is the main problem after implantation and greater toric IOL rotational stability is likely to allow for better visual outcomes. A previous study reported that the mean absolute misalignment ranged from $3.6^{\circ}$ to $3.8^{\circ}$ and IOL misalignment was within $5^{\circ}$ in $78.0 \%$ of eyes and within $10^{\circ}$ in $93.4 \%$ at postoperative year $1 .{ }^{12-14}$ This study showed that mean IOL misalignment was $3.52 \pm 2.75^{\circ}$ at postoperative month 6 , and it was within $5^{\circ}$ in $66.7 \%$ of eyes and within $10^{\circ}$ in $100 \%$. It seems that the vitrectomized status of the eyes do not aggravate misalignment of toric IOL. A similar incidence of rotation even in vitrectomized eyes may be attributable to modified L-shaped haptic design and adhesive properties of the AcrySof toric IOL. ${ }^{8,14}$ Another reason could be no tamponade during vitrectomy.

Potential factors related to IOL rotation include inadvertent placement error, incomplete removal of viscoelastic material, and rotation upon removal of instruments. To alleviate these problems as much as possible, actual implantation axis marking, implantation of toric IOL, and removal of viscoelastic material were carried out after completion of vitrectomy. Furthermore, 23-gauge MIVS has an advantage because it does not need suturing of sclerotomy sites and conjunctiva.

Although there was no difference in preoperative refractive cylinder between the two groups, mean absolute residual refractive cylinder of the toric IOL group was significantly less than the non-toric IOL group at each postoperative period. Previous studies reported that the mean absolute residual refractive cylinder was 0.72 and $0.59 \mathrm{D}$ at postoperative months 3 and $12 .^{13,14}$ This study showed the residual refractive cylinder was 0.60 and $0.57 \mathrm{D}$ at postoperative months 3 and 6. Because of the astigmatic reduction of toric IOL, UCVA of the toric IOL group was significantly better than the non-toric IOL at postoperative months 1, 3, and 6 . Another reason could be due to no vitreoretinal complications related to 23-gauge MIVS.

In this study, eight eyes (53.3\%) in the toric IOL group had macular thickening due to ERM or DME. Postoperative change of macular thickness could change the axial length measurement. ${ }^{18}$ However, Attas-Fox et $a l^{19}$ reported that axial measurement with IOLMaster is less affected by retinal thickening than A-scan ultrasound, particularly DME. It is because A-scan ultrasound measures axial length from the cornea to the vitreoretinal interface, whereas IOLMaster measures it to the retina-retinal pigment epithelium interface. Thus, optical biometry with IOLMaster is the preferred method for axial measurement of patients with macular thickening, which was done in our study.

This study had several limitations. Macular edema was evaluated by 78-D lens not by optical coherence tomography; thus, an accurate relationship could not be estimated between the changes in macular thickness and refractive power or visual acuity. Because of the small number of cases and absence of previous reports, it is difficult to clearly demonstrate the efficacy of toric IOL with regards to the visual acuity in vitrectomized eyes. However, this study showed AcrySof toric IOL had good rotational stability, even in vitrectomized eyes, which has not been reported before. Furthermore, significant astigmatic reduction of the toric IOL group resulted in better UCVA than the non-toric IOL group.

In conclusion, combined 23-gauge MIVS and phacoemulsification with AcrySof toric IOL implantation is an effective method of correcting vitreoretinal diseases and cataract, and pre-existing corneal astigmatism. Further randomized and prospective studies with a larger study population and longer follow-up are necessary to evaluate the efficacy and safety of the combined phacovitrectomy with this IOL, and our study could be a useful reference for future trials. 


\section{Summary}

\section{What was known before}

- AcrySof toric IOL (Alcon Laboratories, Inc., Fort Worth, TX, USA) had good rotational stability and favorable efficacy in patients with cataracts and corneal astigmatism.

\section{What this study adds}

- Combined 23-gauge MIVS and phacoemulsification with AcrySof toric IOL implantation is an effective method of correcting vitreoretinal diseases and cataract and pre-existing corneal astigmatism.

\section{Conflict of interest}

The authors declare no conflict of interest.

\section{References}

1 Chung TY, Chung H, Lee JH. Combined surgery and sequential surgery comprising phacoemulsification, pars plana vitrectomy, and intraocular lens implantation: comparison of clinical outcomes. J Cataract Refract Surg 2002; 28(11): 2001-2005.

2 Demetriades AM, Gottsch JD, Thomsen R, Azab A, Stark WJ, Campochiaro PA et al. Combined phacoemulsification, intraocular lens implantation, and vitrectomy for eyes with coexisting cataract and vitreoretinal pathology. Am J Ophthalmol 2003; 135(3): 291-296.

3 Koenig SB, Mieler WF, Han DP, Abrams GW. Combined phacoemulsification, pars plana vitrectomy, and posterior chamber intraocular lens insertion. Arch Ophthalmol 1992; 110(8): 1101-1104.

4 Azar-Arevalo O, Arevalo JF. Corneal topography changes after vitreoretinal surgery. Ophthalmic Surg Lasers 2001; 32(2): 168-172.

5 Domniz YY, Cahana M, Avni I. Corneal surface changes after pars plana vitrectomy and scleral buckling surgery. J Cataract Refract Surg 2001; 27(6): 868-872.

6 Slusher MM, Ford JG, Busbee B. Clinically significant corneal astigmatism and pars plana vitrectomy. Ophthalmic Surg Lasers 2002; 33(1): 5-8.

7 Park DH, Shin JP, Kim SY. Surgically induced astigmatism in combined phacoemulsification and vitrectomy; 23-gauge transconjunctival sutureless vitrectomy vs 20-gauge standard vitrectomy. Graefes Arch Clin Exp Ophthalmol 2009; 247(10): 1331-1337.

8 Ruhswurm I, Scholz U, Zehetmayer M, Hanselmayer G, Vass C, Skorpik C. Astigmatism correction with a foldable toric intraocular lens in cataract patients. J Cataract Refract Surg 2000; 26(7): 1022-1027.

9 Sun XY, Vicary D, Montgomery P, Griffiths M. Toric intraocular lenses for correcting astigmatism in 130 eyes. Ophthalmology 2000; 107(9): 1776-1781.

10 Till JS, Yoder Jr PR, Wilcox TK, Spielman JL. Toric intraocular lens implantation: 100 consecutive cases. J Cataract Refract Surg 2002; 28(2): 295-301.

11 Patel CK, Ormonde S, Rosen PH, Bron AJ. Postoperative intraocular lens rotation: a randomized comparison of plate and loop haptic implants. Ophthalmology 1999; 106(11): 2190-2195.

12 Bauer NJ, de Vries NE, Webers CA, Hendrikse F, Nuijts RM. Astigmatism management in cataract surgery with the AcrySof toric intraocular lens. J Cataract Refract Surg 2008; 34(9): 1483-1488.

13 Holland E, Lane S, Horn JD, Ernest P, Arleo R, Miller KM. The AcrySof Toric intraocular lens in subjects with cataracts and corneal astigmatism: a randomized, subject-masked, parallel-group, 1-year study. Ophthalmology 2010; 117(11): 2104-2111.

14 Mendicute J, Irigoyen C, Aramberri J, Ondarra A, Montes-Mico R. Foldable toric intraocular lens for astigmatism correction in cataract patients. J Cataract Refract Surg 2008; 34(4): 601-607.

15 Holladay JT, Cravy TV, Koch DD. Calculating the surgically induced refractive change following ocular surgery. $J$ Cataract Refract Surg 1992; 18(5): 429-443.

16 Bergmann MT, Koch DD, Zeiter JH. The effect of scleral cautery on corneal astigmatism in cadaver eyes. Ophthalmic Surg 1988; 19(4): 259-262.

17 Novis C. Astigmatism and toric intraocular lenses. Curr Opin Ophthalmol 2000; 11(1): 47-50.

18 Ueda T, Nawa Y, Hara Y. Relationship between the retinal thickness of the macula and the difference in axial length. Graefes Arch Clin Exp Ophthalmol 2006; 244(4): 498-501.

19 Attas-Fox L, Zadok D, Gerber Y, Morad Y, Eting E, Benamou $\mathrm{N}$ et al. Axial length measurement in eyes with diabetic macular edema: a-scan ultrasound vs IOLMaster. Ophthalmology 2007; 114(8): 1499-1504. 